\title{
Paisagens em movimento: transformações pós- ocupação nos conjuntos habitacionais do Programa Minha Casa Minha Vida
}

\section{Landscape in motion: post-occupations changes in the housing estates of "Minha Casa Minha Vida" Program}

Rafael Alves Orsi - Doutor em Geografia, pela Universidade Estadual Paulista Júlio de Mesquita Filho (UNESP/Rio Claro). Professor Associado no Departamento de Ciências Sociais da Universidade Estadual Paulista "Júlio de Mesquita Filho" (UNESP). E-mail: rafael.a.orsi@unesp.br

\section{Resumo}

O Programa Minha Casa Minha, lançado em 2009, alavancou a produção habitacional brasileira transformando as paisagens das cidades, sobretudo nas áreas periféricas onde conjuntos habitacionais ou complexos de conjuntos habitacionais foram implantados. Refletindo os interesses de múltiplos atores em diferentes escalas, a análise da paisagem urbana, nestes empreendimentos, permite a compreensão das articulações entre atores de atuação global e nacional e as idiossincrasias locais e a vida cotidiana expressas no processo de produção do espaço. Com o intuito de analisar as transformações pós-ocupação nos conjuntos habitacionais que fazem parte do Programa Minha Casa Minha Vida, destacando o movimento antagônico e complementar da escala local e global na composição desta paisagem selecionou-se cinco empreendimentos na cidade de Araraquara/SP/Brasil para o desenvolvimento da pesquisa. Ancorado em pesquisa bibliográfica, observação da paisagem e trabalhos de campo, pode-se averiguar as profundas transformações no espaço que denotam fortes demandas sociais, mas também sonhos e esperanças.

\section{Palavra-chave}

Paisagens. Espaços Urbanos. Conjuntos Habitacionais. Programa Minha Casa Minha Vida.

\begin{abstract}
Released in 2009, the "Minha Casa Minha Vida" Program has been boosted the Brazilian housing production and changes the cities landscape, mainly in peripheral areas where the housing estates or complex of housing estates have been constructed. The urban landscapes analyses reflect the multiples interests and actors (in different scales) and in these housing estate developments are possible understand the relationship between global and national actors and local characteristics with its daily dynamic production of space. This paper aims analyses the post-occupation changes in housing estates from "Minha Casa Minha Vida" Program, highlighting the antagonistic and complementary movement between local and global scales in the structuring of landscape. With this purpose, it was selected five housing estates in Araraquara to developing the research. Supported by basic bibliography, landscape observation and fieldwork, it was possible to verify the space deep changes, what show great social demands in the se housing estates, but show dreams and hopes of its habitants as well.
\end{abstract}

\section{Keywords}

Landscape. Urban Spaces. Housing Estate. "Minha Casa Minha Vida" Program. 


\section{INTRODUÇÃO}

É inegável que a produção habitacional é uma das grandes forças motrizes responsáveis pela alteração e criação de paisagens urbanas. Da criação de espaços planejados a ocupações irregulares - em diferentes áreas -, alteram-se as densidades, os fluxos, o comércio/serviços, a interação com o meio físico, entre outras tantas transformações bastante perceptíveis na paisagem urbana. Menos perceptíveis pela visão, mas profundamente impactantes, são as rupturas que tal produção do espaço pode provocar. Áreas segregadas por barreiras físicas ou sociais, regiões estigmatizadas, espaços do medo e da morte, contrastam com espaços do luxo, da suntuosidade, da salubridade e da segurança.

Da prancheta, muitas vezes fria, do urbanista até a dinâmica social que requalifica e modifica o espaço, transformando as formas de ser e existir nas cidades e, mais especificamente em seus bairros, há processos de ressignificação das estruturas responsáveis pelos seus novos e múltiplos usos, comumente ignorados em fases de elaboração e execução de projetos e na própria concepção das políticas públicas. Por certo que as formas e estruturas que se delineiam nas cidades materializam forças distintas de produção. Da mesma forma, sintetizam e explicitam os interesses nestes processos, tensões e fraturas em sua composição. Se por um lado, é possível analisar a produção do espaço urbano por meio da mercantilização dos espaços da cidade de maneira parcelar e da própria cidade como um todo, por outro, é na dinâmica do cotidiano, na gradativa significação e valoração do espaço, em suas especificidades e de forma particularizada que a paisagem se compõe e recompõe em processos contínuos. Seus usos e troca são colocados em confronto e é desse atrito e tensão que resultam as formas urbanas, ali em seu íntimo, em sua particularidade.

Evidentemente, há poderosas forças estruturantes do espaço urbano, com interesses específicos e que, em maior ou menor grau, coadunam com a ideia de tornar a cidade um polo de atração de recursos. Como defende Harvey (2006), desdobram-se dessa postura diferentes estratégias que buscam tornar a cidade empreendedora e que, na visão do autor, podem trazer impactos deletérios para as cidades em seu conjunto. Contrastante a esta visão, Castells e Borja (1996) defendem a importância do planejamento estratégico e das cidades como atores políticos fundamentais para a atração de recursos e, para tal, devem apresentar mecanismos e estruturas articulados aos interesses globais para desencadear processos de desenvolvimento no local. Ambas as leituras recorrem à lógica global da produção econômica para compreender as transformações nas cidades e, consequentemente, a formação de suas paisagens. 
Se existem forças globais que se realizam nas cidades, o que é inegável, há também uma vida pulsante, com um conjunto de atores (moradores do próprio local) que dinamizam as estruturas e impõem mudanças profundas na escala local a esta dinâmica globalizada. Como destaca Santos (2008, p. 322), "o lugar é o quadro de uma referência pragmática ao mundo". Logo, é no local que a vida acontece e vive-se outro tempo de realização, um tempo mais lento. É imperativo, como defende Magnani (2002), um olhar de perto e de dentro, para compreensão daquilo que acontece no lugar.

Ao voltar o olhar para a dinâmica pós-ocupação nos conjuntos habitacionais do Programa Minha Casa Minha Vida (PMCMV), são notórias as transformações do espaço urbano e a vida impressa nos novos bairros. Considerando esses aspectos, propõem-se, com este artigo ${ }^{1}$, refletir sobre as paisagens urbanas formadas pelo PMCMV, com a preocupação de evidenciar que esta dinâmica reflete demandas, sonhos e peculiaridades expressas em escala local. Ao mesmo tempo, tem como pano de fundo que as escalas global e local apresentam movimentos antagônicos, porém complementares na formação da paisagem urbana. Desta forma, a dimensão global e a local são ubíquas ao longo do texto.

Devido ao PMCMV abarcar diferentes camadas sociais a partir da renda familiar, optou-se por selecionar conjuntos habitacionais vinculados à faixa I do programa, voltada para a população de menor renda e beneficiária de maiores subsídios públicos para a aquisição da moradia. É certo que as dinâmicas singulares de cada empreendimento formam paisagens únicas, mas também são notórias as semelhanças e a repetição de padrões entre alguns empreendimentos. O texto está estruturado no sentido de compreender o significado da paisagem como uma forma coerente com a formação socioeconômica de seu próprio tempo, mas que de alguma maneira carrega as marcas de momentos anteriores. Logo, as escalas temporais e espaciais são elementos fundamentais na estruturação do pensamento sobre as cidades, neste caso particular, na formação das paisagens urbanas dos conjuntos habitacionais.

Focando-se no PMCMV, será destacada a paisagem resultante deste programa habitacional, enfatizando os empreendimentos que formam os conjuntos habitacionais na cidade de Araraquara/SP/Brasil: Anunciata Palmira Barbieri; Romilda Taparelli Barbieri; Maria Helena Lepre Barbieri; Bairro Valle Verde e Jardim do Valle. Para o desenvolvimento da pesquisa, além do diálogo com a literatura, procederam-se saídas a campo para captação de imagens que pudessem elucidar as ponderações.

\footnotetext{
Texto resultante de parte da pesquisa intitula "Qualidade de vida nos conjuntos habitacionais do Programa Minha Casa Minha Vida: confrontando o nível de satisfação dos moradores com suas condições de existência", financiada pelo Conselho na Nacional de Desenvolvimento Científico e Tecnológico (CNPq).
} 
O texto está estruturado em cinco partes, além das considerações finais. Primeiramente, é feita uma apresentação do PMCMV, seguida de seus desdobramentos, quando se mostra sua importância, mas também suas limitações. $\mathrm{Na}$ terceira parte, discute-se o conceito de paisagem, direcionando as reflexões para a leitura do espaço urbano. Na quarta e quinta partes, trata-se das transformações na paisagem pré e pós-ocupação nos conjuntos habitacionais estudados.

\section{PANORAMA SOBRE O PROGRAMA MINHA CASA MINHA VIDA}

Após a extinção do Banco Nacional de Habitação (BNH), em 1986, o Brasil permaneceu por um longo período sem uma política nacional de habitação consistente, com produção de moradias e linhas de financiamentos significativos para o setor. A partir do segundo governo do presidente Luiz Inácio Lula da Silva, iniciado em 2007, traça-se o Plano Nacional de Habitação (PlanHab) - concluído em 2008 -, o qual busca desenvolver estratégias para o setor da habitação até 2023. O documento deixa muito fácil de entender a estratégia de articular uma política de inclusão social com o desenvolvimento e o fortalecimento econômico. Para tanto, neste primeiro momento, foram fundamentais os recursos do Programa de Aceleração do Crescimento (PAC), lançado em 2007, e do Programa Minha Casa Minha Vida (PMCMV), iniciado de 2009.

Após seu lançamento, como já era esperado, o PMCMV impactou sobremaneira no mercado habitacional e também no mercado de terras urbanas em todo o país, uma vez que sua envergadura territorial é de grande abrangência e o montante de recursos financeiros disponibilizados foi significativo. Com o intuito de criar e fortalecer uma política social para a habitação e, ao mesmo tempo, dinamizar a economia nacional, diferentes mecanismos foram implementados. É válido salientar que tais medidas se encontravam no bojo de ações de uma política econômica anticíclica frente à crise econômica internacional iniciada em 2008. Algumas medidas foram direcionadas para o setor habitacional, das quais se destacam:

[i] flexibilização das regras para acesso aos recursos do FGTS, ampliandose os volumes de recursos do Fundo utilizados como subsídios; [ii] redução das taxas de juros, viabilizadas pela redução do risco propiciada pela criação do Fundo Garantidor da Habitação, que aporta recursos para pagamentos das prestações em caso de inadimplência por desemprego e outras eventualidades; [iii] concessão de subsídios diretos para as camadas de baixa renda, integrais para as faixas até três salários mínimos e parciais para as faixas acima de três até 10 salários mínimos (CARDOSO; ARAGÃO, 2011, p. 89). 
Embora o PMCMV apresentasse a preocupação de subsidiar famílias de baixa renda, a distribuição, dentro do espectro de famílias com até 10 salários mínimos, mostrou-se bastante desigual se considerarmos o déficit habitacional no país. Com a previsão de construir um milhão de unidades habitacionais, $40 \%$ destinou-se a famílias de 0 a 3 salários mínimos. Porém, é nesta faixa de renda que se concentrava 90\% do déficit habitacional brasileiro. Sem desconsiderar a importância deste programa habitacional, no que diz respeito ao acesso à terra urbana pelas famílias de menor renda, é evidente sua limitação. As diferentes críticas ao PMCMV não impediram que ele fosse ampliado. Em continuidade àquilo que o governo Lula implementou, sua sucessora - a presidente Dilma Rousseff - lançou em 2011 o PMCMV 2, com metas de construir dois milhões de unidades habitacionais até 2014, nesta sua segunda fase, ano em que foi reeleita para a presidência da República. Em seu segundo mandato, abortado em um processo de impeachment em 2016 - ano de fortes turbulências políticas e de estagnação econômica no Brasil -, o PMCMV entra em sua fase 03, atualizando os valores de financiamento e os subsídios concedidos, criando uma nova faixa de renda para o enquadramento dos beneficiários (faixa 1,5) e reduzindo sua meta de três milhões - anteriormente anunciada pelo governo - para dois milhões de unidades habitacionais. Com a meta reduzida, a ser alcançada até o final de 2018, o programa habitacional continuou na agenda das políticas públicas do governo de Michel Temer, quem assumiu a Presidência da República após o impeachment da presidente Dilma Rousseff.

\section{DESDOBRAMENTOS DO PMCMV}

O desenvolvimento do PMCMV consolida no setor habitacional a tendência delineada por toda a década de 1990, ou seja, a produção habitacional feita pela iniciativa privada, financiamento direto ao consumidor final e, como algo novo característico dessa fase presente nos governos petistas, forte subsídio público (KLINTOWITZ, 2011). No tocante ao mercado imobiliário, Cardoso e Aragão (2011) defendem a existência de um duplo efeito. Por um lado, as empresas que se lançaram no mercado de capitais encontraram sustentação na forte dinamização imobiliária e seus valores de mercado foram alavancados por um mercado consumidor ascendente e pelas garantias dadas pela injeção de recursos públicos. Por outro lado, ampliou-se a demanda por terras e as nefastas práticas de especulação imobiliária. Neste movimento, a habitação, mais uma vez é vista como simples mercadoria, fornecida pelo mercado - ainda que com subsídios - e com baixa agregação ao conjunto urbano, resultando em espraiamentos da mancha urbana, bem como segregações e estigmatizações de bairros inteiros. 
De acordo com Klintowitz (2011), a estrutura do modelo do PMCMV é totalmente coerente com as mudanças institucionais implementadas no Brasil na segunda metade da década de 1990 no esteio da reforma do Estado. Logo, vê-se um Estado: fomentador e regulador; empenhado na desburocratização na celebração de contratos; voltado para o gerenciamento focado nos resultados; muito mais preocupado com o volume - quantidade - do que com a qualidade dos empreendimentos. Assim, não causa estranheza o fato de muitos empreendimentos serem instalados em áreas distantes, com pequena infraestrutura e com qualidade de construção duvidosa. Esta última característica traz como efeito a possibilidade de execução de projetos de baixa qualidade sendo, comumente, alvo de fortes críticas provindas de estudos acadêmicos, meios de comunicação, opositores do programa e, não raro, é objeto de processos junto ao Ministério Público.

A partir de uma lógica puramente econômica, sobretudo pelo lado dos empreendedores privados, os projetos são voltados para a maximização dos lucros, trabalhando com os parâmetros mínimos exigidos pelo programa e, em alguns casos, sem cuidados técnicos que garantam a qualidade da construção. A padronização dos projetos como estratégias de barateamento empobrece o ato de morar/habitar. De acordo com Nascimento e Tostes (2011):

O processo de morar, que deveria pressupor escolhas, participação e tomadas de decisão em diversos níveis e ao longo do tempo, se vê empobrecido e resumido à mera relação de compra de um produto como outro qualquer, com o esvaziamento e empobrecimento de sua dimensão política (NASCIMENTO; TOSTES, 2011, não paginado).

Se os projetos trazem problemas em suas concepções arquitetônicas, a questão não é diferente do ponto de vista urbanístico. Sem um controle efetivo do poder público local em relação aos projetos implementados, a localização desses conjuntos tende a ser nas áreas mais afastadas, cujo valor da terra é menor. Como denomina Maricato (2013), na periferia da periferia. Obviamente, neste cenário são encontrados diferentes problemas advindos da periferização e espraiamento das cidades. Falta qualidade aos projetos de maneira geral, não apenas nos aspectos técnicos elaborados pela iniciativa privada, mas, fundamentalmente, na estruturação política do projeto, no seu sentido social, nas articulações com o contexto urbano e os planos diretores municipais. Tanto a localização dos empreendimentos, os materiais, os conceitos de morar e fazer parte do conjunto urbano tem sido negligenciado em grande parte dos projetos. Como defendem diferentes autores, tudo indica que se tem fomentado a segregação 
socioterritorial, por meio de medidas que fortalecem a especulação imobiliária e promovem moradias de baixa qualidade em áreas periféricas.

A despeito da importância e dos avanços proporcionados pela criação da Política Nacional de Habitação (PNH), do Sistema Nacional de Habitação de Interesse Social (SNHIS), do Conselho das Cidades, Conselhos Municipais de Habitação, Plano Locais de Habitação, PlanHab, todos criando uma nova institucionalidade para a produção habitacional e da própria cidade, os resultados até agora do PMCMV parecem indicar a prevalência do mercado em relação aos interesses sociais da moradia e do direito à cidade. A análise de Nascimento Neto, Moreira e Schussel (2012) aponta uma ruptura entre os pressupostos da PNH e, evidentemente, o PlanHab e a implantação do PMCMV, o que tem gerado distorções no sentido de equacionar os problemas de habitação no Brasil.

Da mesma forma, Rodrigues (2011) defende que apesar da criação do Ministério das Cidades pelo governo Lula, as políticas urbanas foram vistas como políticas setoriais desconsiderando o território. Desta maneira, a implantação de conjuntos habitacionais tem apresentado projetos que se descolam ou ignoram o espaço urbano produzido com suas tensões e idiossincrasias, reproduzindo problemas que de fato se propõe a sanar, como o gritante déficit habitacional e as decorrentes fraturas sociais urbanas. Mesmo com a existência de importantes instrumentos de planejamento e ordenação do espaço, como os Planos Diretores (PD), pouco se tem avançado em sua utilização para conter e minimizar os problemas advindos da especulação imobiliária, do espraiamento das cidades e da ocupação de áreas fragilizadas do ponto de vista socioeconômico e ambiental.

\section{APONTAMENTOS SOBRE A PAISAGEM}

Ao se propor a análise da paisagem como elemento gerador e estruturador das reflexões, inevitavelmente questiona-se a envergadura do conceito para sustentar as reflexões e apontamentos. A paisagem, de certa maneira, constitui-se um conceito polissêmico. Das definições enciclopédicas, quase todas tributárias de uma compreensão de paisagem como um produto estático captado pela visão ${ }^{2}$, até definições sofisticadas que identificam a paisagem como resultante de processos distintos que se acumulam e interagem de forma dialética no espaço, o conceito traz o homem como ser criador e cognoscente da paisagem. Em um diálogo e trocas constantes com o meio no qual está inserida, a sociedade - com

O Dicionário Houaiss de Língua Portuguesa traz a seguinte definição: "extensão de território que o olhar alcança num lance; vista, panorama; conjunto de componentes naturais ou não de um espaço externo que pode ser apreendido pelo olhar" (HOUAISS; VILLAR; FRANCO, 2009, p. 1413). 
seus diferentes grupos - lê, relê, produz, reproduz, cria diferentes valorações e estratégias de vivência em seu espaço. Ao se confrontar com a paisagem, é notório este movimento. Considerando as proposições de Moreira (2010):

Vai-se, assim, do visível para o invisível e do invisível volta-se para o visível, num movimento dialético da intelecção no curso do qual a paisagem - aquilo que no fundo se quer ver compreendido - se torna o concreto-pensado. No caminho da ida, as relações são lidas da paisagem para as relações estruturais mais íntimas. Mergulha-se na paisagem, a partir da observação da localização e distribuição dos objetos espaciais que a compõem em busca do conhecimento das conexões que levem ao conhecimento da estrutura (MOREIRA, 2010, p. 115).

Não parece descabido, mas antes importante, em um esforço interpretativo da paisagem, buscar múltiplos níveis que possam ampliar a leitura do espaço a partir da articulação com outros elementos da senso-percepção em sua composição. No movimento de ida e volta proposto por Moreira (2010), os sons e os odores parecem se articular à visão e formam também uma paisagem olfativa e uma paisagem sonora (FORTUNA, 2013), os quais, gradativamente, compõem uma totalidade. Mesmo que fluído, efêmero e ditado por temporalidades, os odores e os sons marcam a paisagem.

As formas, carregadas de significados, exprimem conteúdos passíveis de análise e capazes de auxiliar na elucidação dos quadros sociais do presente. Para Santos (2008, p. 103), “a ideia de forma-conteúdo une o processo e o resultado, a função e a forma, o passado e o futuro, o objeto e o sujeito, o natural e social". A morfologia, portanto, traz a história de sua configuração que, em si, é tensa e dialética. A paisagem conforma poderosas forças globais que atuam sobre o território, mas ao mesmo tempo não é alheia ao próprio local, com os interesses conflitantes dos múltiplos agentes atuantes nesta escala, e, obviamente, também traz as características físico-naturais do local, muitas vezes de forma marcante. É evidente, então, a composição das paisagens por intermédio de elementos bióticos, abióticos e noóticos ou da sociedade, como destaca Troppmair (2004), atuando sobre a constituição física-natural desses espaços.

Para Bertrand (2007), ainda que fortemente ligado à Teoria Geral dos Sistemas $^{3}$, a ação do homem deve ser incluída no sistema (como um subsistema) dando maior complexidade à produção das paisagens para além das considerações apenas de fluxos de matéria e energia de cunho ecológico.

Ao se buscar aproximações que orientem para uma leitura humanística da paisagem, em primeiro plano os destaques não são mais os elementos físicos, os

Para um maior aprofundamento, sugere-se a leitura de Bertalanfy (1973). 
fluxos (matéria, energia, mercadorias, pessoas etc.) ou a natureza desumanizada, mas sim a percepção do indivíduo em relação ao conjunto e em sua dinâmica. Salgueiro (2001), analisando este caráter na geografia humanista, destaca a importância da subjetividade e a centralidade do indivíduo. Para a autora supracitada:

na geografia humana, verifica-se o acentuar do facto da paisagem ser um território visto e sentido, cada vez mais subjetivo e elaborado pela mente. O enfoque centra-se no indivíduo, nas suas práticas e nas representações que elabora do mundo exterior, as quais condicionam, por sua vez, o comportamento (SALGUEIRO, 2001, p. 45).

Enquanto espaço construído, a paisagem comporta uma interpretação do que é exterior ao indivíduo, mesmo ela sendo um constructo das relações sociais. Mas também permite uma análise a partir do indivíduo, relativa à sua vivência e às interpretações carregadas de sentimentos de empatias e antipatias pelo espaço. Tanto em uma quanto em outra interpretação é significativo o papel das paisagens no comportamento e desenvolvimento humano e social. Obviamente, a ação é social, mas esta é sobre um espaço criado que não é um objeto morto. Harvey (2006) assevera que "a consciência dos moradores urbanos influencia-se pelo ambiente da experiência, do qual nascem as percepções, as leituras simbólicas e as aspirações. Em todos esses aspectos, há uma tensão permanente entre forma e processo, entre objeto e sujeito, entre atividade e coisa" (HARVEY, 2006, p. 170).

Neste movimento, destaca-se aqui a configuração das cidades, onde são criadas rupturas marcantes no espaço, tanto em sua produção como em sua percepção. Não causa nenhuma estranheza identificar nas cidades espaços vinculados ao medo, à insegurança, os quais, objetivamente, também são os locais da insalubridade, áreas inacabadas, com aspetos de restos de cidade em uma cidade fluída. Há verdadeiros "puxadinhos" urbanos, contrastantes com uma cidade do luxo, dos fluxos, da salubridade e da segurança. Uma cidade cindida é produzida e reproduzida e, obviamente, percebida. Ao estudar as paisagens do consumo, Ortigoza (2010) chama a atenção para uma paisagem que é totalmente distinta (paisagem do consumo) e choca-se com a paisagem das periferias. Há uma tensão entre o desejável e o não desejável.

A produção dos espaços de consumo (ou um tipo específico de consumo) acontece em partes específicas e selecionadas nas cidades. Objeto de investimentos e grandes preocupações estéticas, busca-se identificar as cidades como um todo a estes espaços, entendidos como superiores devido aos intensos fluxos comerciais e de capitais, símbolos da inserção, consumo e referências globalizadas. Certamente, esta imagem da cidade volta-se para sua própria população, mas fundamentalmente, direciona-se para os agentes externos, fator 
este que é imperativo em um ambiente de alta competitividade ou guerra de lugares, de acordo com Santos (2008), entre as cidades. No entanto, não como antítese ao centro, mas como complementaridade, as periferias são intensas em seu dinamismo e também produzidas e reproduzidas por agentes em diferentes escalas - do global ao local. Porém, intenta-se "escondê-las", já que estes espaços representam normalmente uma paisagem indesejável.

As imagens da periferia, sempre vistas de longe, não são estranhas à sociedade de forma geral, dado o bombardeio feito pela mídia de maneira massiva. Romantizada em telenovelas, espetacularizadas e demonizadas em programas policiais ou, mais ou menos, cruas em documentários, as periferias são expostas com frequência e comumente identificadas com uma paisagem pouco convidativa e, muitas vezes, com o próprio espaço do medo. Foge do escopo do trabalho, mas é válido salientar que em uma sociedade do medo a imagem da periferia, da pobreza ou daqueles que a representam são fontes de fobias para parte da população. Na modernidade líquida, analisada por Bauman (2009), a mixofobia marca o comportamento das pessoas e também a paisagem das cidades, que se encontram cada vez mais cindidas, muradas e vigiadas.

As paisagens na periferia apresentam grande dinamicidade e, mesmo guardando uma lógica em sua produção, seus aspectos em muitas vezes são caóticos. Com fraco controle do poder público sobre os espaços públicos e também sobre os privados, as transformações fogem das normatizações vigentes no planejamento e gestão urbanos, imprimindo no espaço um mosaico que reflete necessidades imediatas, funcionalidades, demandas econômicas, desejos por singularização e adaptações ao seu estilo de vida (comumente compulsório). Tal dinâmica, somada aos recursos escassos, às baixas qualificações técnicas, aos materiais de reuso ${ }^{4}$, dentre outras peculiaridades, evidencia a precariedade e o inconcluso. Mas também torna clara a vida que flui nestes espaços: como espaços de vida, de criatividade, de lutas e esperanças.

Tais características são evidentes em ocupações espontâneas, mas não é preciso grandes esforços para identificá-las também em áreas de ocupação planejada. Ao observar a dinâmica dos conjuntos habitacionais do PMCMV são notórias as transformações e a ressignificação do espaço, que, em um primeiro momento, é vazio de sentido, cartesiano e burocrático, mas ganha vida ao ser ocupado efetivamente por seus moradores. Alguns desses pontos serão tratados na seção seguinte.

\footnotetext{
$4 \quad$ Materiais de reuso, neste caso, não possuem nenhum vínculo com questões ambientais ou apelos estéticos, mas sim com as limitações econômicas em adquirir materiais novos.
} 


\section{PAISAGEM NO PROGRAMA MINHA CASA MINHA VIDA (PRÉ- OCUPAÇÃO)}

O PMCMV, lançado em 2009, indubitavelmente, transformou a paisagem de inúmeros municípios em todas as regiões do Brasil. Até o segundo semestre de 2016, haviam sido entregues cerca de 2,6 milhões de unidades habitacionais e estavam contratadas mais cerca de 4,2 milhões $^{5}$. O número expressivo de construções marca as cidades e impacta em sua dinâmica, sobretudo quando se considera a aglomeração causada com infraestrutura precária, comércios e serviços muito incipientes ou inexistentes, equipamentos urbanos e serviços públicos deficitários e a localização periférica que espraia as cidades e segregam a população dessas áreas. Tais críticas, presentes em inúmeros estudos, recaem principalmente nas construções enquadradas na faixa I do programa, a qual é voltada para a população de mais baixa renda e aporta grandes subsídios governamentais.

Não é nenhuma novidade que o déficit habitacional brasileiro representa um grave problema social a ser superado, o qual impacta na vida das pessoas de forma geral e na produção das cidades. Certamente, o PMCMV traz os méritos de combater tais déficits habitacionais que maculam a sociedade, originam e desencadeiam uma série de outros problemas. No entanto, é sabido que a lógica da produção do PMCMV é primeiramente econômica, buscando promover uma política anticíclica que fizesse frente aos desdobramentos da crise econômica de 2008. Conforme Amore (2015):

O Minha Casa Minha Vida é, na origem, um programa econômico. Foi concebido pelos ministérios de "primeira linha" - Casa Civil e Fazenda em diálogo com o setor imobiliário e da construção civil, e lançado como Medida Provisória (MP 459) em março de 2009, como uma forma declarada de enfrentamento da chamada crise dos subprimes americanos que recentemente tinha provocado a quebra de bancos e impactado a economia financeirizada mundial (AMORE, 2015, p. 15).

Com tal lógica em sua concepção, a política pública habitacional do PMCMV se sujeita a múltiplos grupos de interesses atuantes em diversas escalas (agentes financeiros, incorporadoras, empreiteiras, políticos locais, especuladores imobiliários), sendo os futuros moradores, de forma questionável, chamados de beneficiários, o grupo mais passivo do conjunto. Certamente, há de se considerar os limites colocados pelos custos da construção, mas que não são (ao menos não deveriam ser) limitantes para a implementação democrática do programa. Com os custos de produção sempre ajustados aos valores financiados pelo programa,

\footnotetext{
$5 \quad$ Em todas as faixas do programa.
} 
os empreendedores privados buscam as terras urbanas para os loteamentos nas localizações mais baratas das cidades, independentemente de sua localização.

Ainda como estratégia de barateamento da construção, empregam-se materiais de baixa qualidade, no limite do aceitável, a metragem de construção é sempre a mínima exigida pelas normas do programa, o projeto em inúmeras vezes é repetido, buscando economia de escala na produção, o número de casas contíguas é elevado ao limite, mesmo que para isso tenha que se utilizar como subterfúgio o "lançamento" de loteamentos e conjuntos habitacionais distintos um ao lado do outro. Essas características formam uma paisagem de produção industrial das moradias, da produção massificada em série e despersonalizada. Assim, é notória a produção funcional da moradia e da cidade. A Figura 1 representa tal característica da padronização e produção em série dos conjuntos habitacionais.

Figura 1 - Produção em série das unidades habitacionais - casas geminadas (2015)

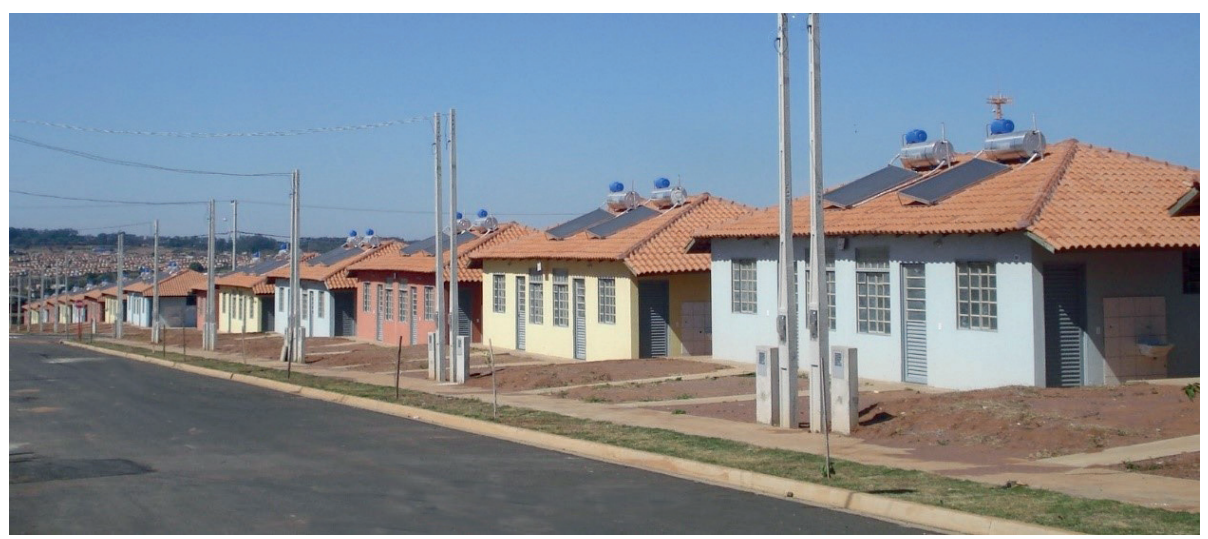

Fonte: O autor, 2015.

Em um universo como o da construção civil, onde há infindáveis possibilidades de materiais, projetos e designs, o repetitivo e a produção em série das casas, reforçam no plano do concreto a condição de limitação dos futuros moradores e sua condição de massificados, não personalizados pelo programa. A unidade habitacional e o "beneficiário" são entendidos como dados estatísticos que, posteriormente organizados em conjuntos, vão apontar o desempenho do programa. Se esta macroleitura, em um primeiro momento, mostra-se verdadeira, a vida que estes espaços ganham no pós-ocupação o transformam de maneira singular e profunda. Ainda que cada um dos conjuntos possa trazer os traços de sua gênese, como algo que os une e os identificam, a pós-ocupação evidencia as idiossincrasias na formação desses espaços. Forma-se uma identificação 
com o novo bairro, o que refletirá na formação da paisagem que, no limite da ação do privado, atua na composição de todo o espaço. As paisagens que antes da ocupação evidenciavam a produção em série com uma lógica da produção industrializada e indiferente ao local, após a ocupação a lógica passa a ser a da vida cotidiana com tempos, olhares e desejos distintos.

\section{TRANSFORMAÇÕES NO ESPAÇO PÓS-OCUPAÇÃO}

Para exemplificar o que foi apresentado nas seções anteriores, foram selecionados cinco conjuntos habitacionais construídos de maneira contígua na cidade de Araraquara/SP. Os conjuntos habitacionais em questão são: 1) Anunciata Palmira Barbieri; 2) Romilda Taparelli Barbieri; 3) Maria Helena Lepre Barbieri; 4) Bairro Valle Verde; e 5) Residencial Jardim do Valle. Os três primeiros formam o bairro Laura Molina, com 1.334 casas. O bairro Valle Verde conta com 754 casas e o Jardim do Vale com 560. No total, são 2.648 casas já entregues na porção norte da cidade, afastada aproximadamente 10 quilômetros das áreas centrais. Na Figura 2 é possível dimensionar a distância das áreas centrais.

Figura 2 - Localização periférica dos conjuntos habitacionais estudados na cidade de Araraquara/SP (área estudada em destaque no círculo vermelho, na porção norte)

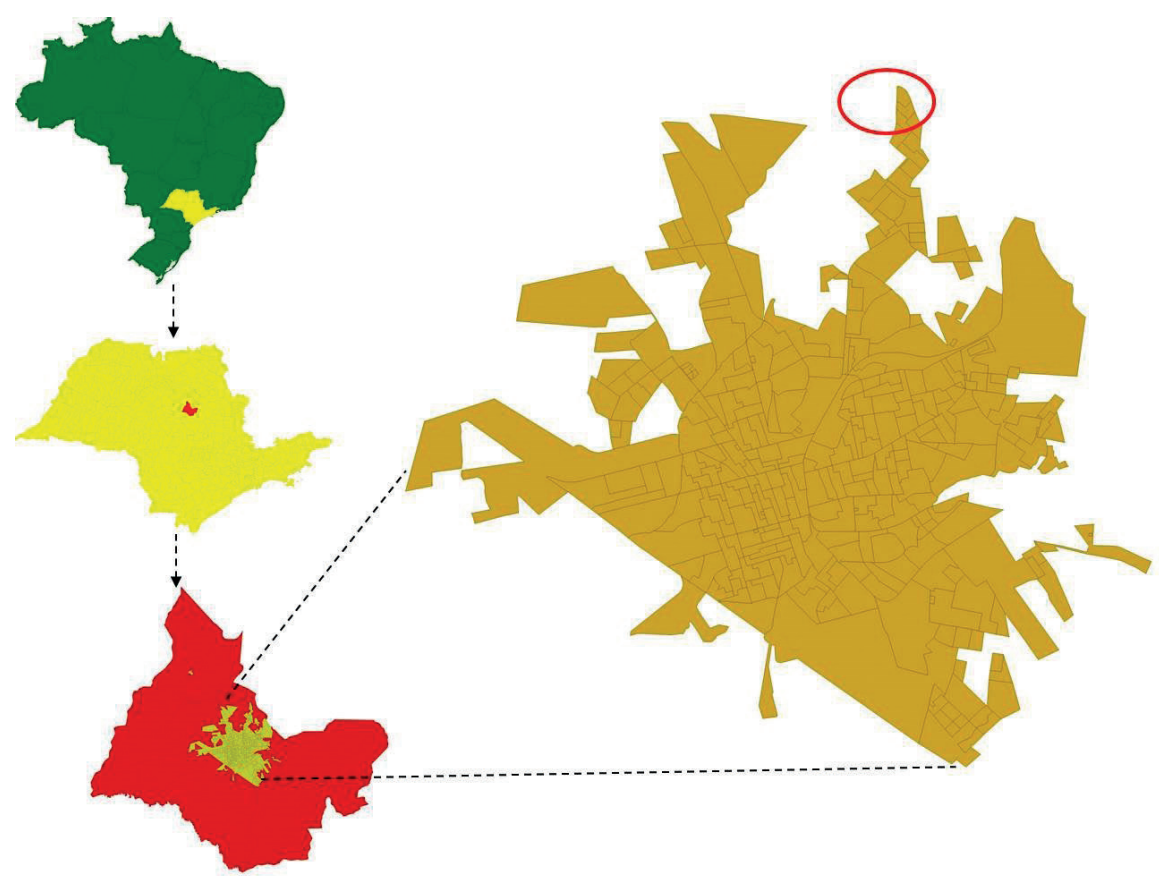

Elaboração: O autor, 2016. 
Estima-se um acréscimo de aproximadamente onze mil pessoas nesta área, decorrente da ocupação dos conjuntos habitacionais. Todas elas enfrentando carências relativas à falta de serviços públicos e privados, comércio incipiente, grande distância das áreas centrais e falta de equipamentos urbanos. Esses problemas têm se mostrado comuns em diversos empreendimentos financiados pelo PMCMV, notadamente na faixa I. Se, por um lado, há demandas não atendidas, o que representa grandes dificuldades para os moradores, por outro lado, alguns dos próprios moradores (recém-chegados) veem nestas demandas, concernentes a comércio e serviços, possibilidades de complementação de renda e sobrevivência.

Em um conjunto de bairros populares, estritamente residencial, imediatamente após a ocupação vê-se surgir atividades comerciais e de serviços que gradativamente mudam a paisagem e a vida do lugar. No entanto, essas atividades comerciais e a prestação de serviços são realizadas de maneira irregular e/ou informal, uma vez que as unidades habitacionais não poderiam ser utilizadas para fins comerciais. Neste processo de modificação da paisagem, observa-se um mosaico de usos mistos da casa: garagens são transformadas em oficinas, papelarias, mercearias, lanchonetes; muros carregam as propagandas dos empreendimentos, dos produtos e dos serviços oferecidos; esquinas apresentam placas de orientação para alguns estabelecimentos; espaços públicos destinados a praças e áreas de lazer abrigam lanchonetes; na rua (espaço público) em frente à casa, trailers de lanches são fixados.

Todas estas transformações e usos marcam a paisagem de forma indelével e evidenciam as estruturas da produção desse espaço. É importante frisar que estes tipos de comércios denotam baixíssimos investimentos e uma velocidade muito lenta em sua reprodução (retorno do capital), porém, rápida o suficiente para auxiliar na subsistência cotidiana da família. As Figuras 3, 4 e 5 mostram algumas dessas características da paisagem.

Figura 3 - Uso comercial no espaço da garagem

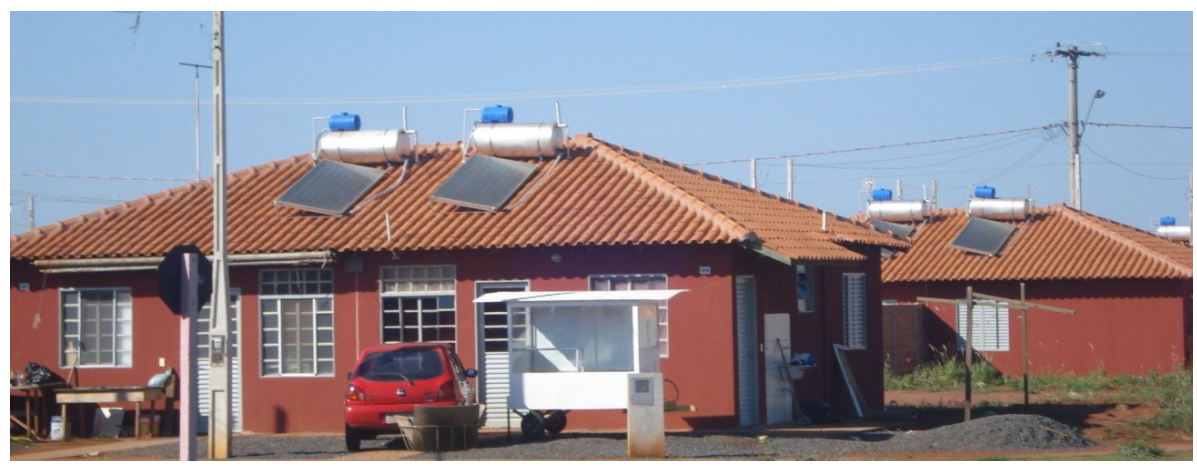

Fonte: O autor, 2016. 
Figura 4 - Uso comercial no espaço da sala de estar

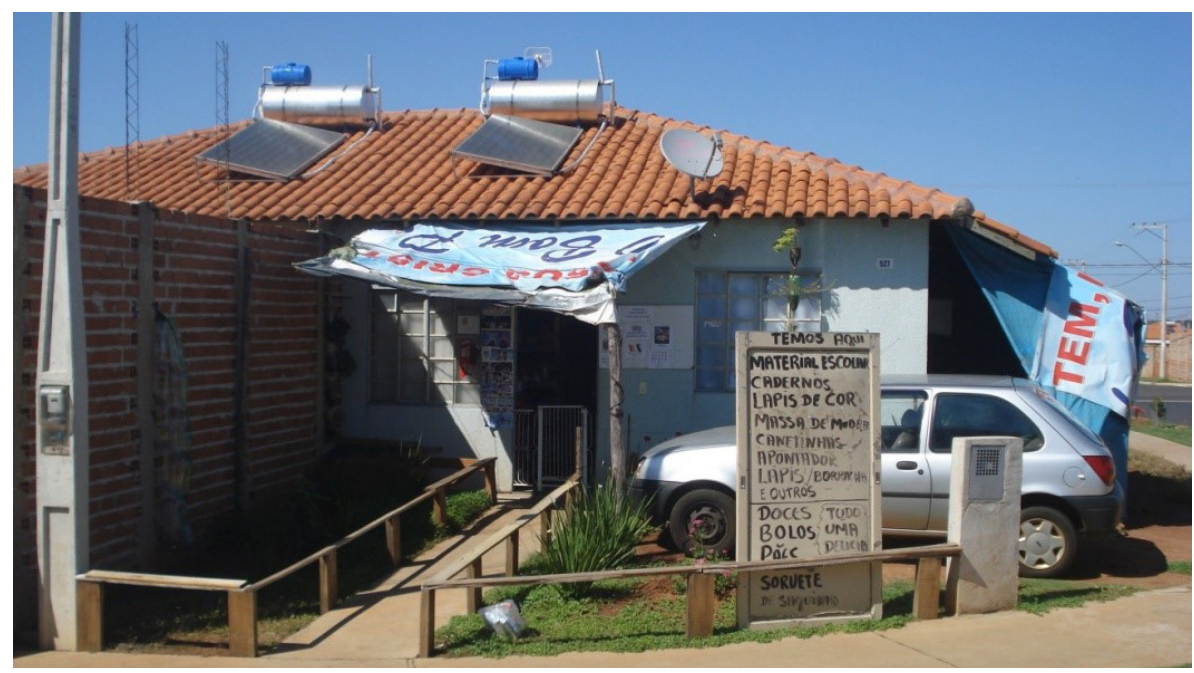

Fonte: O autor, 2016.

Figura 5 - Placas indicando produtos vendidos e serviços prestados

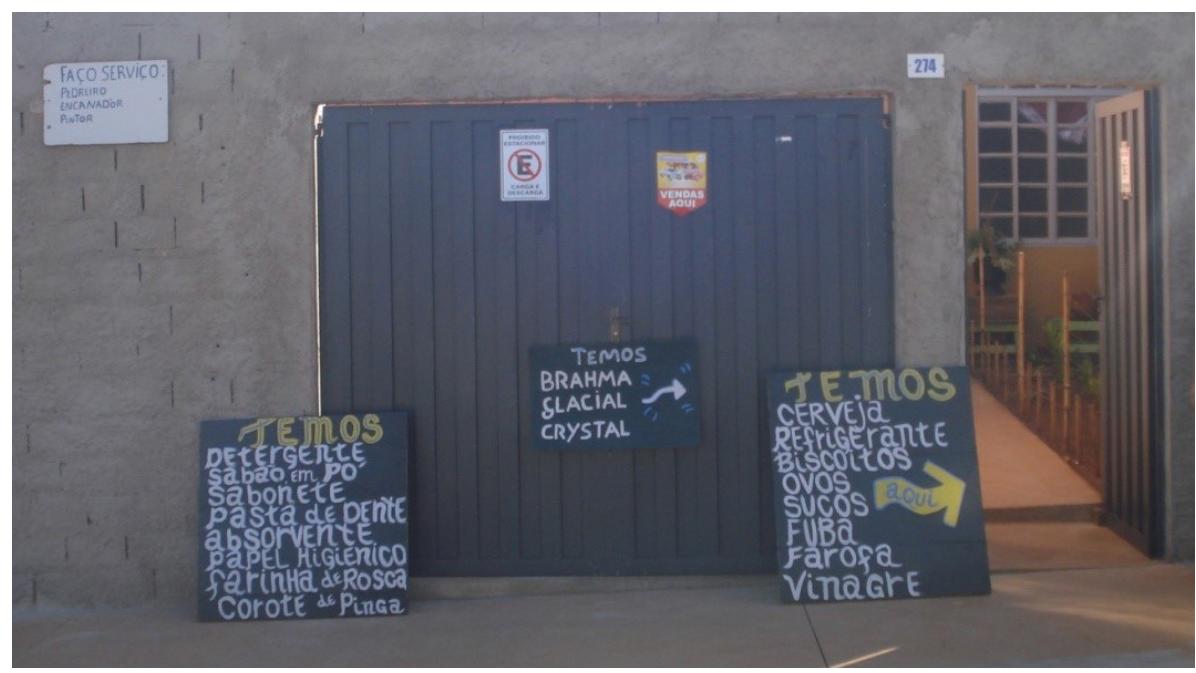

Fonte: O autor, 2016.

Algumas atividades destacam-se nos bairros pelo maior número de estabelecimentos, como: mercearias, lanchonetes (considerando os carrinhos de rua), cabeleireiras, manicures e pedicures. Especificamente, a prestação desses três últimos serviços está vinculada a experiências anteriores à mudança para o bairro. Ao se mudar, o prestador trouxe consigo sua atividade, ainda que precise 
renovar sua carteira de clientes. Além desses comércios e serviços que ocorrem com maior frequência, constatou-se uma grande diversidade de outras atividades, tais como: oficina mecânica, bicicletaria, depósito/revenda de bebidas, papelaria, barbearias, depósito/revenda de gás de cozinha, serralheria e venda hortaliças. Todas estas atividades estão espalhadas pelos bairros.

Assim como as atividades comerciais, as transformações das casas, de uma forma geral, marcam de maneira profunda as mudanças na paisagem do bairro. Refletindo as condições financeiras e os gostos pessoais de seus moradores, a paisagem ganha novas tonalidades que a afastam de seu aspecto anterior de produção em série. Neste caso, ao refletir a dinâmica da sociedade e suas condições materiais, a paisagem pode ganhar tons dramáticos, como a garagem de lona, falta de muros separadores das casas - comprometendo a privacidade e a segurança -, roupas estendida voltadas para a rua, móveis que não couberam na casa acomodados pelo lado de fora etc. A Figura 6 evidencia bem a questão.

Figura 6 - Lona utilizada como cobertura para garagem, extensão e isolamento da área de serviço

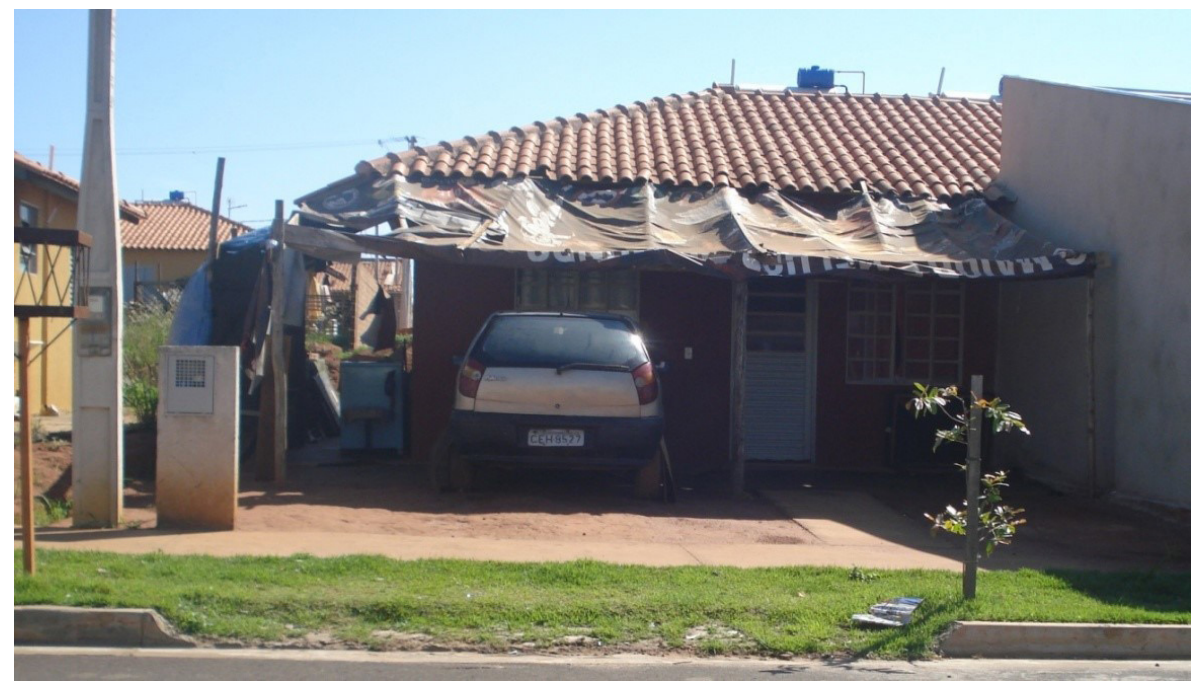

Fonte: O autor, 2016.

É válido salientar que, apesar da paisagem trazer a vida que a anima, a estrutura de sua gênese está presente o tempo todo. As imagens tornam este fato perceptível e ao caminhar pelas ruas do bairro e ter contato com seus moradores é possível perceber a formação do espaço e a composição de uma paisagem que é formada por agentes em diferentes escalas e intensidades. O setor financeiro e o incorporador com seus olhares distantes, entendendo o empreendimento como 
uma atividade comercial, portanto, o espaço urbano como valor de troca, traçam os conjuntos habitacionais, estabelecem o público-alvo em conformidade com o previsto pela política de habitação que norteia o PMCMV e executam o projeto com uma lógica distante do local, estabelecendo as estruturas mestras desse bairro. Pela escala local, os moradores subvertem de algum modo esta lógica que lhe é estranha e imprimem no espaço uma nova configuração, concernente à sua vida cotidiana. A paisagem resultante dessas articulações traz os processos de produção social do espaço e as tensões inerentes a ele.

\section{CONSIDERAÇÕES FINAIS}

A produção do urbano comporta múltiplos agentes, todos com expectativas, desejos, poderes e estratégias diferentes na produção desse espaço. Em uma economia capitalista, na qual o espaço passa a ser compreendido como uma mercadoria de grande rentabilidade, as relações entre esses diversos agentes se complexifica e é potencializada pela globalização das ações, cujos agentes podem trabalhar com uma lógica de reprodução global e se descolar totalmente dos interesses locais. Como afirma Harvey (1980), o espaço é uma mercadoria especial, pois ninguém pode prescindir dele para sua existência. No entanto, o existir enquanto algo concreto choca-se com os interesses abstratos na produção das cidades, em especial no mercado habitacional. Se, no primeiro caso, a preocupação é fundamentalmente com as condições de vida apresentada pelas cidades e seus bairros, no segundo caso, a preocupação maior são com as estratégias para maximizar a renda com a terra e a reprodução do próprio capital. Tais conflitos entre o valor de uso e o valor de troca e as paisagens resultantes desse processo são perceptíveis na produção das cidades e apresentam-se de forma muito nítida e, por vezes, dramática nos conjuntos habitacionais do PMCMV.

Preocupando-se em captar as transformações na paisagem, especificamente nos conjuntos habitacionais dos bairros Laura Molina, Valle Verde e Jardim do Valle, em Araraquara/SP, observou-se a área em dois momentos distintos, isto é, antes da ocupação e pós-ocupação. Como destacado anteriormente, as transformações são muito evidentes denotando as características da população que passa a viver nestes bairros, produzindo o espaço e reproduzindo-se em sua existência cotidiana. Enquanto na pré-ocupação encontra-se uma paisagem desenraizada, despersonificada e massificada, coerente com os objetivos das incorporadoras, rentistas imobiliários, construtoras, entre outros agentes, o pós- 
ocupação mostra a dinâmica dos moradores e suas condições de existência, nível de formação, relações sociais e sua visão de mundo. É o cotidiano que começa a marcar a paisagem de forma indelével.

A paisagem do PMCMV guarda a hibridez desses dois momentos e dos objetivos distintos que ambos possuem em relação a este mesmo espaço. É certo que as especificidades de cada lugar e cada grupo os tornam de certa maneira distintos, mas os processos que os formam guardam aproximações e semelhanças. Soma-se ainda a esta hibridez a ação do Estado, tanto pelo que fez quanto pelo que não fez. Se as execuções são tímidas, sobram espaços abertos esperando pelos investimentos municipais. Áreas destinadas a praças e construção de equipamentos urbanos de lazer ainda a espera das execuções, áreas verdes sem a devida manutenção, atrasos na entrega de unidades de saúde, enfim, há toda uma estrutura realizada e uma não realizada que compõem a paisagem dos bairros.

À guisa de uma finalização, é possível afirmar que a paisagem do PMCMV na área analisada traz tensões, atritos (entre público e privado, formal e informal) e apresenta um aspecto de inacabado que não é um simples porvir, há algo de não realizado e irrealizável. Não parece que uma vida urbana renovada, como defende Lefèbvre (2001), seja algo factível na área. A qualidade de vida, considerando apenas a observação da paisagem, apresenta-se em níveis muito elementares, dificultada pela própria gênese do projeto. Acreditando-se que tais características sejam recorrentes aos empreendimentos do PMCMV faixa I, é evidente que o programa necessita de aprimoramentos para corrigir os desdobramentos na vida cotidiana dos bairros após sua ocupação.

\section{REFERÊNCIAS}

AMORE, C. S. Minha Casa Minha Vida para iniciante. In: AMORE, C. S.; SHIMBO, L. Z.; RUFINO, M.B.C. (org.). Minha Casa... e a cidade?: avaliação do programa minha casa minha vida em seis estados brasileiros. Rio de Janeiro: Letra Capital, 2015. p. 11-27.

BAUMAN, Z. Confiança e medo na cidade. Rio de Janeiro: Zahar, 2009.

BERTALANFY, L. V. Teoria geral dos sistemas. Petrópolis: Vozes, 1973

BERTRAND, G. A paisagem entre a natureza e a sociedade. In: PASSOS, M. M. (org.). Uma geografia transversal e de travessias: o meio ambiente através dos territórios e das temporalidades. Maringá: Editora Massoni, 2007. p. 213-234. 
CARDOSO, A. L.; ARAGÃO, T. A. A reestruturação do setor imobiliário e o Programa Minha Casa Minha Vida. In: MENDONÇA, J. G.; COSTA, H. S. M. (org.). Estado e capital imobiliário: convergências atuais na produção do espaço urbano brasileiro. Belo Horizonte: Editora Arte, 2011. p. 81-104.

CASTELLS, M.; BORJA, J. As cidades como atores políticos. Novos Estudos - CEBRAP, São Paulo, n. 45, p. 152-166, jul. 1996. Disponível em: http:// novosestudos.uol.com.br/v1/files/uploads/contents/79/20080626_as_ cidades_como_atores.pdf. Acesso em: 05 mar. 2016.

FORTUNA, C. Identidades, percursos, paisagens culturais: estudos sociológicos de cultura urbana. Coimbra: Imprensa da Universidade de Coimbra, 2013. Disponível em: https://digitalis-dsp.uc.pt/jspui/ bitstream/10316.2/23478/1/E-book_Identidades_percursos_paisagens\%20 culturais.pdf?ln=pt-pt. Acesso em: 26 ago. 2016.

HARVEY, D. A justiça social e a cidade. São Paulo: Hucitec, 1980.

HARVEY, D. A produção capitalista do espaço. São Paulo: Annablume, 2006.

HOUAISS, A; VILLAR, M. S.; FRANCO, F. M. Dicionário Houaiss da Língua Portuguesa. Rio de Janeiro: Objetiva, 2009.

KLINTOWITZ, D. C. Como as políticas habitacionais se inserem nos contextos de reforma do Estado? A experiência recente do Brasil. Revista Pensamento e Realidade, São Paulo, v. 26, n. 3, p. 101-120, 2011. Disponível em: http:/ / revistas. pucsp.br/index.php/pensamentorealidade/article/view/8080/5967. Acesso em: 15 jan. 2014.

LEFÈBVRE, H. O direito a cidade. São Paulo: Centauro, 2001.

MAGNANI, J. G. C De perto e de dentro: notas para uma etnografia urbana. Revista Brasileira de Ciências Sociais, São Paulo, n. 17, v. 49, p. 11-29, jun. 2002. Disponível em: http://www.scielo.br/pdf/rbcsoc/v17n49/a02v1749.pdf. Acesso em: 10 set. 2016.

MARICATO, E. Cidades rebeldes: é questão urbana, estúpido. Le Monde Diplomatique, ano 07, n. 73, ago. 2013. Disponível em: http://www. diplomatique.org.br/artigo.php?id=1465. Acesso em: 10 fev. 2014.

MOREIRA, R. Pensar e ser em geografia: ensaios de história, epistemologia e ontologia do espaço geográfico. São Paulo: Contexto, 2010. 
NASCIMENTO, D. M.; TOSTES, S. P. Programa Minha Casa Minha Vida: a (mesma) política habitacional no Brasil. Vitruvius (Arquitextos), São Paulo, n. 133, ano 12, jun. 2011. Disponível em: http://www.vitruvius.com.br/revistas/ read/arquitextos/12.133/3936. Acesso em: 27 jan. 2014.

NASCIMENTO NETO, P; MOREIRA, T. A.; SCHUSSEL, Z.D.G.L. Conceitos divergentes para políticas convergentes: descompassos entre a política nacional de habitação e o programa Minha Casa, Minha Vida. Revista Brasileira de Estudos Urbanos e Regionais, v. 14, n. 01, p. 85-98, mai. 2012. Disponível em: http:// www.anpur.org.br/revista/rbeur/index.php/rbeur/article/view/1907/1870. Acesso em: 20 jan. 2014.

ORTIGOZA, S. A. G. Paisagens do consumo: São Paulo, Lisboa, Dubai e Seul. São Paulo: Cultura Acadêmica, 2010.

RODRIGUES, A. M. A política urbana no governo Lula. Ideias, v. 1, n. 03, p. 61-80, 2011. Disponível em: http://www.ifch.unicamp.br/ojs/index.php/ ideias/article/view/615/489. Acesso em: 15 jan. 2014.

SALGUEIRO, T. B. Paisagem e geografia. Finisterra, Lisboa, n. 72, p. 37-53, 2001. Disponível em: http://revistas.rcaap.pt/finisterra/article/view/1620/1315. Acesso em: 10 set. 2016.

SANTOS, M. A natureza do espaço: técnica e tempo, razão e emoção. São Paulo: Edusp, 2008.

TROPPMAIR, H. Biogeografia e meio ambiente. Rio Claro-SP: Divisa, 2004. 